\title{
HISTORY
}

or

\section{A CASE OF ANEURISM}

OF THE

FEMORAL ARTERY,

FOR WHICH THE OPERATION

or

TYING THE EXTERNAL ILIAC ARTERY

WAS PERFORMED.

By CHARles COLliER, Esq.

SURGEON TO THE FORCES.

COMMUNICATED BY

SIR JAMES MACGRIGOR.

Read Feb. 6, 1816.

JOHN MORRISY, of the second battalion of the 3oth regiment, aged 24, of a full and masculine habit, was admitted into St. Elizabeth's Hospital, under my care, Thursday, August 24, for aneurism of the femoral artery of the right side; the tumor was about three inches in length, and two in breadth, and extended to within an inch of Poupart's ligament. The pulsation was powerful, and gave the feeling of a strong thrill, with considerable resistance to the propulsion of the blood; there 
was a cicatrix where a ball had entered, on the top, about two and a half, or three inches from Poupart's ligament; the skin was not discoloured; the limb was of the same temperature and plumpness as the other.

I learned that the patient had been wounded by a musket ball on the 18th of June, which had penetrated at the cicatrix alluded to, and had remained in the limb; that he had lost a considerable quantity of blood at the time, but that nothing particular occurred during the healing, and he had been discharged the hospital, apparently cured, on the 12th of July. On the 17th of July he was placed as orderly in the Notre Dame Hospital, where he continued, being at times very dissipated, until the 18th of August, when, being unable to go on with his duties, he, for the first time, shewed the tumor to the medical officer in charge, and was instantly taken under treatment.

This hospital being broken up, was the cause of the patient coming under my care on the day stated.

The aneurism I considered to have been formed by the injury done to the vessel, in the passage of the ball, and to have been consequently of two. months' duration; the constitution was vigorots and good, and fearing lest the pulsation or any toss of health might occasion the cicatrix to ulcerate, I 
determined not to delay securing the external iliac artery, an operation which I judged to be requisite in order to save life, and to be urgently called for, from the visible enlargement of the tumor. He was confined to bed, kept on spare diet, and the bowels were evacuated preparatory to the operation, which I performed on Monday, August 28, at twelve, in presence of Mr. Gunning, surgeon in chief, Mr. Neil, deputy inspector, Dr. Wray, physician to the forces, and most of the medical officers at Brussels.

I made a semicircular incision, which began three-fourths of an inch on the interior of the inner ring, had its base on Poupart's ligament, and terminated at about one inch and a half from the anterior superior spinous process of the ilium, horizontally with the commencement. The fascia of the external oblique, after being exposed, was detached from Poupart's ligament, to the same extent, and in the same direction; on turning it up, the lower edge of the internal oblique, and the beginning of the cremaster muscles, with the spermatic cord passing through the inner ring, were distinctly seen. Some fibres of the internal oblique, having their origin from the ligament, were then divided in order to give me room. The cord was held aside with the flap formed by the incision, while I enlarged the inner ring with the handle of the knife, and detached the peritoneum with my finger, so as to enable me to feel the artery, which I found 
covered by, and closely connected to some small glands, the largest of which I removed. Having separated the artery, I passed a director under it, and the gentlemen present being satisfied that it alone was raised, I passed a probe, armed with a ligature, along the groove, and secured it: the pulsation in the aneurismal tumor instantly ceased. The edges of the wound were approximated by one suture. Two small arteries sprang during the operation, but there was no blood lost deserving the least consideration.

In one hour after the operation the patient felt easy; the pulse was 90 and soft ; the heat of both limbs much alike, and somewhat below the natural temperature. At four there was great diminution of heat on the whole limb, and the foot and toes were quite cold; he was anxious, and complained of great numbness; hot flannels were applied, and used with gentle friction; bottles filled with hot water were fixed to the soles of the feet, and along the leg. At seven the anxiety had increased, and the pain was excessive, with a sense of great coldness; he tossed about, and was very restless; some discoloured patches were discovered on the calf of the leg. Through the night the pulse was generally full, varied from 80 to 92 , and for a time intermitted; he was irritable, and the countenance anxious; complained of the most excruciating pain, the same feeling of coldness, and want of power over the leg; was otherwise easy. Two 
anodyne draughts were administered, but he słept little, or not at all; towards morning he thought himself easier; the warmth to the limb was kept up the whole night, but the instant the applications for this purpose were removed, the temperature sunk.

Through the day of the 29th, the anxiety and restlessness rather increased, accompanied with the same pain and numbness; the discoloured patches had enlarged; the skin was soft, the pulse full, with hardness; it never exceeded 100; tongue white and moist. Two doses of castor oil were administered, but without effect on the bowels; the limb was lightly swathed in flannel, and men were kept constantly sitting by his bed-side to keep their hands on his leg and foot; the hot bottles continued; during this night he slept well, but complained of excessive pain whenever he awoke.

On the 30th, the wound of the operation was dressed, and appeared irritable ; the pulse was full, and very hard; the tongue white and moist; the skin hot ; expressed himself easier, but was restless and complained of the same want of feeling; thermometer on the thigh rose to $86^{\circ}$; small doses of neutral salts were administered every three hours, and $16 \mathrm{oz}$. of blood taken away, which was buffed and cupped. The patient seemed generally relieved by the subtraction of blood, but complained of aching pains below the knee. Two spots of 
sphacelus appeared about the ancle-joint; bowels were evacuated towards the evening, and the evacuations were natural; he slept but little during the night; was in much pain, and tossed about in great anxiety; perspired at times freely. On the morning of the 31 st the pulse had risen, was very full and hard; the patient complained of pain over the abdomen, increased by pressure; the wound was very highly inflamed; $12 \mathrm{oz}$. of blood were taken away; it was found equally buffed and cupped with the former; the bowels were kept open, and poultices applied to the wound. He appeared better and easier through this day, than at any time since the operation; the limb had a cadaverous odour; towards night the pulse being still hard; and having still pain of abdomen, $8 \mathrm{oz}$. of blood were further subtracted; the thigh was discoloured ; there was no increase of natural heat, or diminution of the sense of numbness, or of the general restlessness. He passed the night in great anxiety and distress, and in the morning the whole limb, for some three inches above the knee, was livid, and had vesicated in several places. He took a little wine at times through the day, but the constitutional powers gradually sunk, and he died at four in the afternoon of the 1st of September.

\section{Dissection.}

On opening the abdomen in the usual manner, there appeared a general flush of the intestines; 
the reflected peritoneum was of its usual transparency, and the cœcum was adhering to it by lymph over the iliac muscle. The ligature was on the artery close to Poupart's ligament, about an inch below the giving off the circumflex, and some quarter of an inch from giving off the epigastric. The wound of the operation was made as 1 intended. There was a small communication between the femoral artery and vein at the side of the tumor, about an inch and a half below the origin of the profunda; on the superior part the covering of the aneurism was formed by the sheath of the vessels, and the fascia of the thigh. The profunda was neither thickened nor enlarged. The whole limb was in a state of gangrene. 